\title{
Effect of stem cell transplantation of premature ovarian failure in animal models and patients: A meta-analysis and case report
}

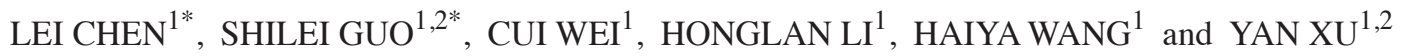 \\ ${ }^{1}$ R\&D Department, Nanjing Regenerative Medicine Engineering and Technology Research Center, Nanjing, Jiangsu 210046; \\ ${ }^{2}$ R\&D Department, Regenerative Medicine Center, The Second Military Medical University, Shanghai 200433, P.R. China
}

Received October 18, 2016; Accepted June 6, 2017

DOI: $10.3892 /$ etm.2018.5970

\begin{abstract}
Stem cell transplantation has been considered a promising therapeutic approach for premature ovarian failure (POF). However, to date, no quantitative data analysis of stem cell therapy for POF has been performed. Therefore, the present study performed a meta-analysis to assess the efficacy of stem cell transplantation in improving ovarian function in animal models of POF. In addition, a case report of a patient with POF subjected to stem cell treatment was included to demonstrate that stem cell therapy also contributes to the recovery of ovarian function in patients. Published studies were identified by a systematic review of the PubMed, Embase, and Cochrane's library databases, and references cited in associated reviews were also considered. Data regarding follicle-stimulating hormone (FSH), estradiol (E2), ovarian weight, follicle count, the number of pregnancies and other parameters, including delivery route and cell type, were extracted. Pooled analysis, sensitivity analyses, subgroup analyses and meta-regression were performed. In the case of POF, transvaginal ultrasound (TVS), abdominal ultrasound (TAS) and color Doppler flow imaging (CDFI) were performed to observe the endometrial morphology and blood flow signals in the patient. Overall, pooled results from 16 pre-clinical studies demonstrated that stem cell-based therapy significantly improved FSH levels [standardized mean difference $(\mathrm{SMD})=-1.330 ; 95 \%$ confidence interval (CI), -(2.095-0.565); $\mathrm{P}=0.001]$, E2 levels ( $\mathrm{SMD}=2.334$; 95\% CI, 1.350-3.319; $\mathrm{P}<0.001)$, ovarian weight $(\mathrm{SMD}=1.310$; 95\% CI, 0.157-2.463; $\mathrm{P}=0.026)$, follicle count $(\mathrm{SMD}=1.871$; 95\% CI, 1.226-2.516; $\mathrm{P}<0.001$ ), and the number of pregnancies (risk ratio $=1.715,95 \% \mathrm{CI}, 1.213-2.424 ; \mathrm{P}=0.002$ ). The results
\end{abstract}

Correspondence to: Dr Yan $\mathrm{Xu}, \mathrm{R} \& \mathrm{D}$ Department, Nanjing Regenerative Medicine Engineering and Technology Research Center, 108 Ganjiabian East, Yaohua Street, Nanjing, Jiangsu 210046, P.R. China

E-mail:xuyan63628@sina.com

*Contributed equally

Key words: stem cell, cell transplantation, premature ovarian failure, ovarian function, meta-analysis of TVS and TAS demonstrated improved ovarian size and endometrial thickness in the patient with POF after MSC treatment. Of note, a rich blood flow signal in the endometrium was observed on CDFI. It appeared that stem cell-based therapy may be an effective method for the resumption of ovarian function in a patient and in animal models of POF; however, large-scale and high-quality future studies are required to confirm the present findings due to heterogeneity.

\section{Introduction}

Premature ovarian failure (POF) is a disease characterized by amenorrhoea, infertility, estrogen deficiency, reduced follicles and elevated gonadotropin prior to the age of 40 years $(1,2)$. POF occurs in 1-3\% of women, and its incidence rate has demonstrated an increasing tendency in recent years $(3,4)$. Women suffering from POF may have an increased risk of osteoporosis, cardiovascular disease and dementia (5). Furthermore, it has been reported that POF may lead to a series of health problems, such as depression, anxiety as well as compromised quality of marital life and sexual function (6). The etiology of POF is complex, and remains to be fully elucidated, but it has been reported to be associated with factors including autoimmune responses, infection, genetic factors, iatrogenic effects of treatments such as chemotherapy, radiotherapy and surgery, and endocrine dysfunction (7,8). At present, management of POF essentially involves hormone replacement and infertility treatment, particularly hormone replacement therapy (HRT), which is considered as the clinical treatment of choice $(9,10)$. However, HRT does not fundamentally restore normal ovarian function. In addition, a study has demonstrated that HRT may increase the risk of breast cancer (10). Therefore, novel therapeutic strategies that restore ovarian function of patients with POF are required.

Stem cell therapy has been identified as a potential and alternative therapeutic means of potentially repairing and restoring the normal function of damaged tissues, presenting a novel approach for clinical treatment of POF (11). Previous pre-clinical studies have revealed that the transplantation of stem cells into animal models of POF restores ovarian function and generates immature oocytes $(12,13)$. However, research on stem cell transplantation for the treatment of POF is mostly limited to preliminary animal experiments. As such, clinical studies have rarely been reported (14-16) and there is a lack of 
systematic pre-clinical studies providing a sufficiently large sample to confirm the safety and efficacy of stem cell treatment. The aim of the present study was to perform a systematic review and meta-analysis of stem cell treatment in animal models of POF, and to provide a further proof-of-concept for the clinical treatment of POF $(17,18)$.

Furthermore, the present study reported on a case of POF treated by autologous MSCs transplantation in order to demonstrate that stem cell transplantation may elicit the same clinical effects in patients as in animal models of POF.

\section{Materials and methods}

Ethics statement. The case report in the present study was performed with the informed consent of the patient according to the Declaration of Helsinki and was approved by the Society of Medical Ethics of Jiangsu Province (Nanjing, China). The patient agreed for ultrasound and scanning images to be published in the present study.

Literature search. A systematic search was performed to identify all studies on stem cell therapy in animal models of POF using electronic databases (PubMed, Embase and the Cochrane Library) published until up to June 2016. The key words used for relevant literature searches were 'stem cell', 'cytotherapy', 'premature ovarian failure' and 'premature ovarian insufficiency', and search results were limited to studies in English language. In addition, relevant studies were also identified by manual searching of the reference lists of all relevant articles and previous review articles.

Inclusion and exclusion criteria. Studies were included if they met all of the following criteria: i) Full-text articles; ii) randomized or a case control studies; iii) $\mathrm{POF}$ or premature ovarian insufficiency (POI) animal models; iv) animal models of POF or POI were assigned to a group of topical or systemic therapy with stem cells or a control group (without stem cells); and v) one of the following outcomes was included: Follicle-stimulating hormone (FSH), estradiol (E2), ovarian weight, the number of pregnancies and follicle count.

Studies were excluded according to the following criteria: i) No randomized or case control study as they are rare; ii) studies with incomplete reporting of data or insufficient sample size; iii) studies that were duplicates of included studies; iv) non-English literature; v) studies utilizing stem cell factor; vi) no inclusion of the desired outcomes; vii) studies on animal models of POF which also had other diseases; and viii) reviews, editorials, non-animal studies, letters and conference papers without sufficient data.

Data extraction. Data including first author name, country, publication year, study design (randomized or case control), source and type of stem cells, species of animals, details of the animal model, route of delivery, number of stem cells and time of transplantation, intervention methods, follow-up duration, as well as the major outcome measures were extracted from each included study by two independent authors (S.G. and L.C.). For articles only reporting data as figures, the values of mean and standard deviation (SD) or standard error (SE) were extracted from images by two independent authors.
Case report. A 38-year-old woman was diagnosed with POF due to chronic usage of hormone drug treatment for polycystic ovary syndrome. The major clinical symptoms in the patient were amenorrhea for 2 years, accompanied by hectic fever and sweating, soreness and weakness of waist and knees and vaginal dryness. Review of medical history, physical examination and laboratory tests were performed prior to the cell therapy. The patient had no remarkable family and medical history. Laboratory tests revealed persistently high serum FSH and luteinizing hormone (LH) levels, as well as low E2 levels, consistent with POF. Prior to the treatments, it was explained to the patient that the treatment was experimental; the patient's informed consent was obtained. With approval of the Society of Medical Ethics of Jiangsu Province, the patient with POF was scheduled for autologous MSC transplantation (19). The patient began to receive MSC treatments on January 4, 2014, and the total number of treatments was 6 (one treatment per month). The patient was transplanted with MSCs (100 $\mathrm{ml} 0.9 \%$ normal saline, at a concentration of $2 \times 10^{7}$ cells $/ \mathrm{ml}$ for the first time and at a concentration of $1 \times 10^{7} / \mathrm{ml}$ for the latter 5 times) by intravenous injection. After MSC therapy, the patient was subjected to transvaginal ultrasound (TVS) and transabdominal ultrasound (TAS) detection on March 6, May 15 and July 24, 2014, respectively. In addition, transvaginal color Doppler flow imaging (CDFI) also was performed to assess the endometrial blood flow.

Statistical analysis. For each outcome measure, the sample size as well as mean value and standard deviation were recorded for the treatment groups and control groups. The effect size of stem cell therapy was calculated, and standardized mean difference (SMD) with 95\% confidence intervals (CIs) was used for analysis of continuous data, whereas dichotomous data were presented as risk ratios (RRs) with 95\% CIs. The heterogeneity among the studies was assessed by using Cochrane's Q test and $\mathrm{I}^{2}$ statistics, and $\mathrm{I}^{2}>50 \%$ was considered indicative of a significant heterogeneity (20). A random-effects model was used to estimate the pooled results instead of a fixed-effects model, to minimize the influence of potential heterogeneity between the studies. A sensitivity analysis was performed to evaluate the stability of the results by subsequently excluding individual studies. Subgroup analyses and meta-regression were performed to assess the impact of certain study characteristics on the outcomes and to reveal potential sources of heterogeneity. In addition, potential publication bias was evaluated by funnel plot, Egger's test and Begg's test (21). A non-parametric 'trim-and-fill' analysis was also performed to further evaluate the possible effect of publication bias on the results of the meta-analysis. A two-sided P-value $<0.05$ was considered to indicate a statistically significant difference. All statistical analyses were performed by using Stata software (version 12.0; Stata, College Station, TX, USA).

\section{Results}

Search results and characteristics of included studies. In Fig. 1, a flow diagram illustrating the study selection procedure is presented. A total of 297 studies were retrieved after initial search of the databases. Among these, 254 articles were excluded by screening the titles and abstracts, mainly 


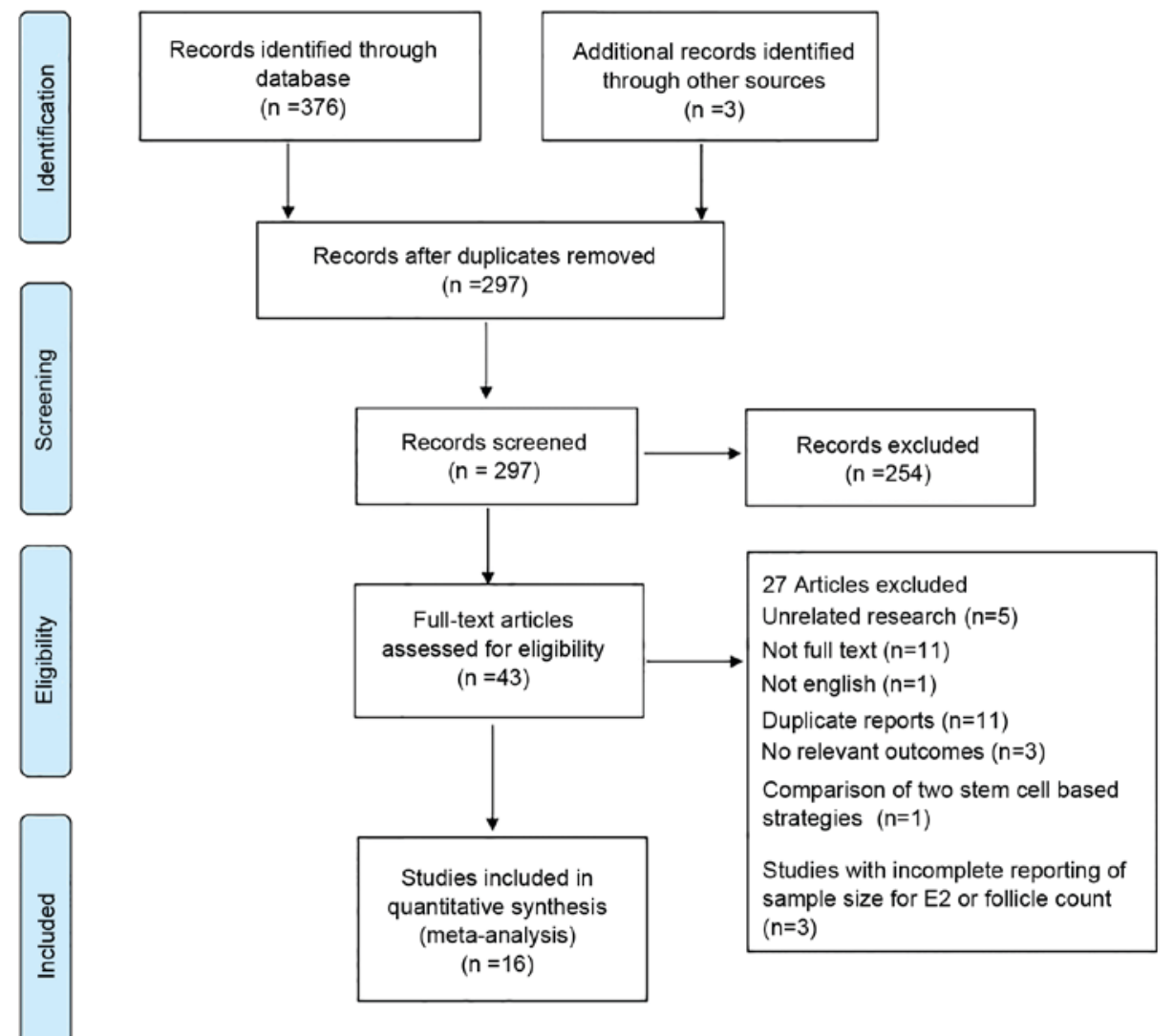

Figure 1. Identification process for eligible studies.

due to being irrelevant to the objective of the study, or due to being literature reviews or duplicate reports. The remaining 43 articles underwent a more detailed evaluation. Among those articles, 5 did not involve animal models of POF, 11 did not have any full-text version available online, 1 was not written in English, 3 were duplicates of another study, 3 did not provide the appropriate outcomes, 1 study compared two types of cells from different sources, and 3 studies did not provide the sample size for E2 or the follicle count. Finally, 16 studies $(12,22-36)$ were included in the meta-analysis, whose details are presented in Table I.

Among the included studies, 13 were from China (12,23-28,30-35), one was from Egypt (22), one was from Turkey (29) and one was from the United States (36). In the animal models, POF was mainly induced by chemotherapy (15 studies) (12,22,26-28,32-36) and Gr cobalt $60 \gamma$ (11)-ray irradiation (1 study) (26). Among these 16 studies, 1 reported four outcome measures (12), 7 reported three outcome measures $(22-24,26,28,33,35), 1$ reported two outcome measures (30) and 7 reported only one outcome measure $(25,27,29,31,32,34,36)$. The stem cells used in the treatment group included human umbilical cord MSCs, adipose-derived stem cells, ovarian granulosa-like cells derived from human-induced pluripotent stem cells (PSCs), human amniotic epithelial cells, human cord blood mononuclear cells, human endometrial MSCs, bone marrow-derived MSCs, skin-derived MSCs and microRNA-17-3p-transfected human-induced PSCs, with the total numbers of the transplanted cells ranging from $1 \times 10^{3}$ to $3 \times 10^{7}$. In particular, Song et al (23), Zhang et al (25), Kilic et al (29), Wang et al (32) and $\mathrm{Fu}$ et al (35) included multiple comparisons with various stages of the follicles and Song et al (23) included multiple comparisons with different delivery routes of stem cells. Lai et al (31) included comparisons with different sources of stem cells. All of these comparisons were included in the meta-analysis. Overall, it contained 59 comparisons, with 724 animals for the stem cell treatment group, and 660 animals for the control group. The follow-up duration of these studies varied from 2 to 8 weeks (Table I).

Meta-analysis. The major outcomes for the eligible studies were the levels of FSH and E2, ovarian weight, follicle count and the number of pregnancies. A random-effects model instead of a fixed-effects model was used for assessing the effect size of stem cells on FSH, E2, ovarian weight and follicle count due to significant heterogeneity, while a fixed-effect models was adopted for the analysis of the number of pregnancies. The pooled analysis suggested that stem cell transplantation led to a statistically significant improvement in FSH [SMD=-1.330; 95\% CI, -(2.095-0.565); $\mathrm{Z}=3.41$, degrees of freedom (df)=7; P=0.001; Fig. 2], E2 (SMD=2.334; 95\% CI, 1.350-3.319; $\mathrm{Z}=4.65 ; \mathrm{df}=10 ; \mathrm{P}<0.001$; Fig. 3), ovarian weight $(\mathrm{SMD}=1.310 ; 95 \% \mathrm{CI}, 0.157-2.463 ; \mathrm{Z}=2.23 ; \mathrm{df}=2 ; \mathrm{P}=0.026$; Fig. 4), follicle count (SMD=1.871; 95\% CI, 1.226-2.5160; $\mathrm{Z}=5.69$; $\mathrm{df}=31 ; \mathrm{P}<0.001$; Fig. 5), as well as the number of pregnancies $(\mathrm{RR}=1.715 ; 95 \% \mathrm{CI}, 1.213-2.424 ; \mathrm{Z}=3.05$; $\mathrm{df}=3$; $\mathrm{P}=0.002$; Fig. 6) as compared with those in the control group. In addition, no heterogeneity in the meta-analysis of the number of pregnancies was noted $\left(\mathrm{I}^{2}=0 \% ; \chi^{2}=1.01 ; \mathrm{P}=0.798\right)$, but there was a significant heterogeneity in the meta-analysis of 


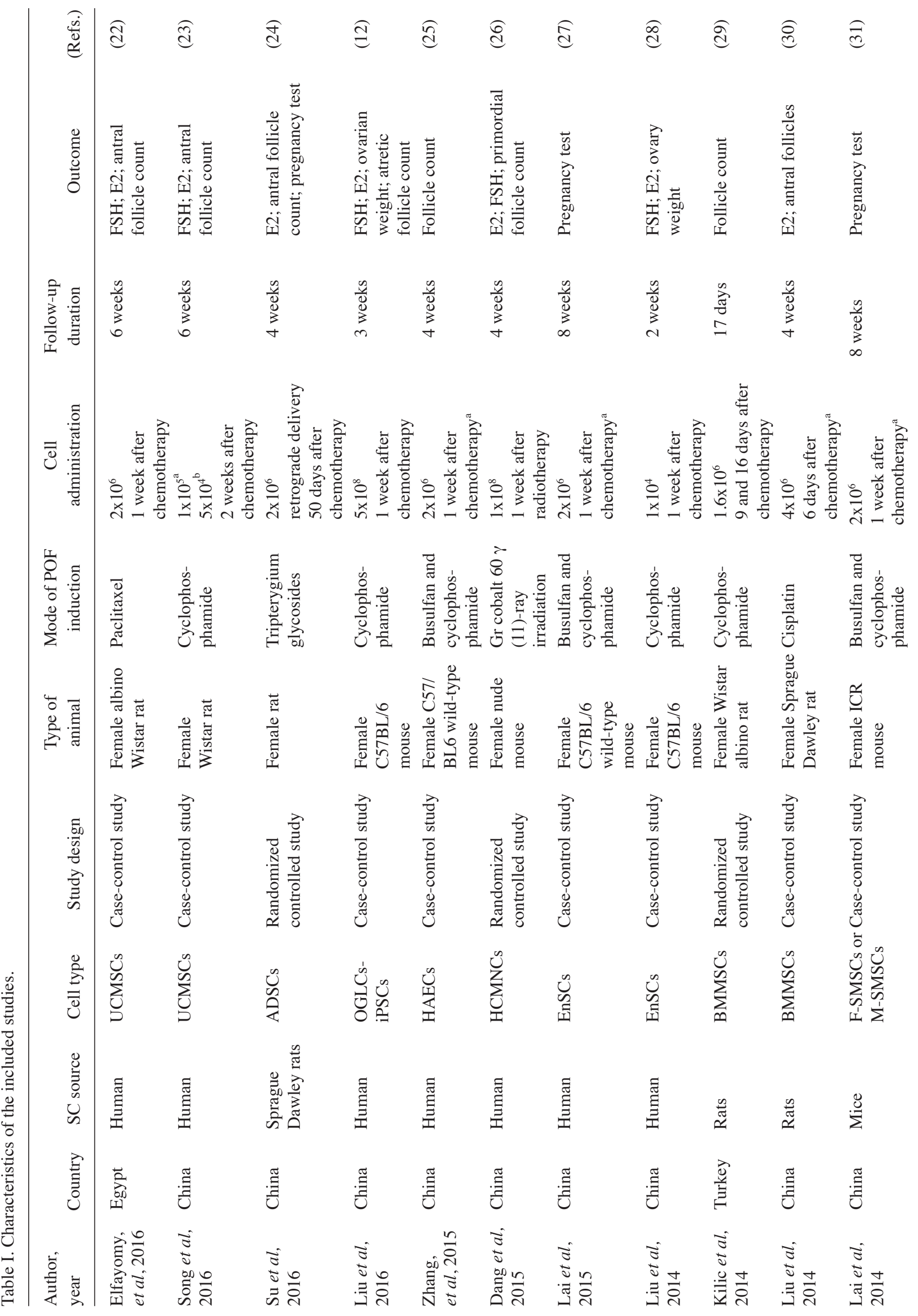




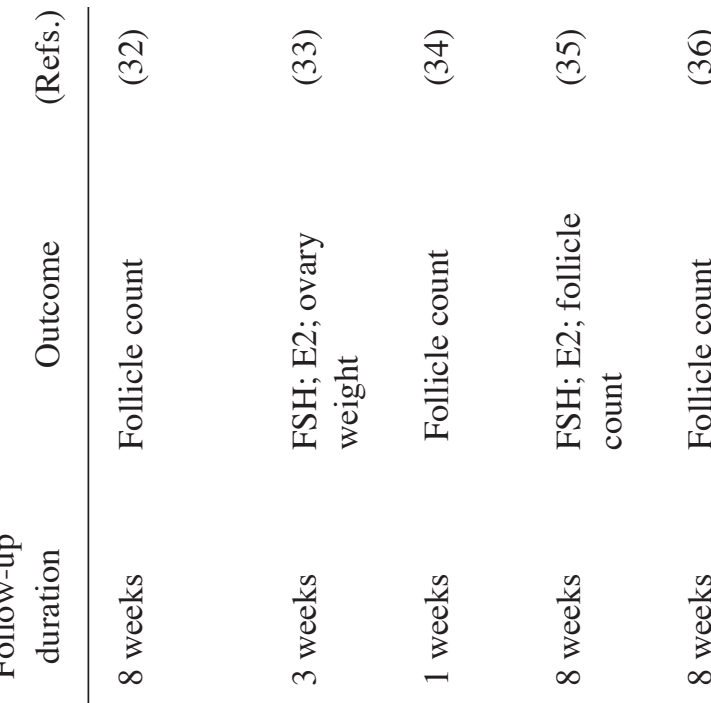

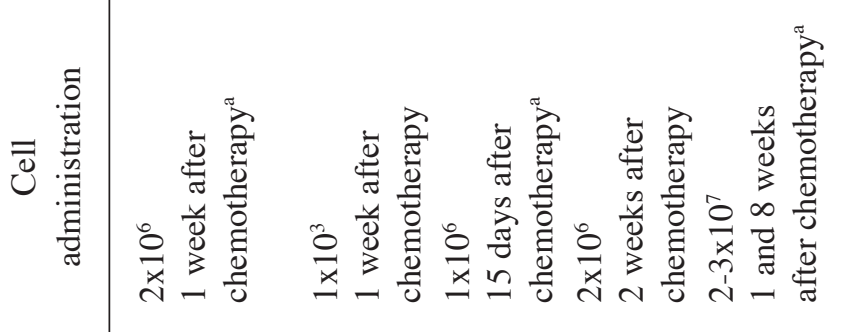

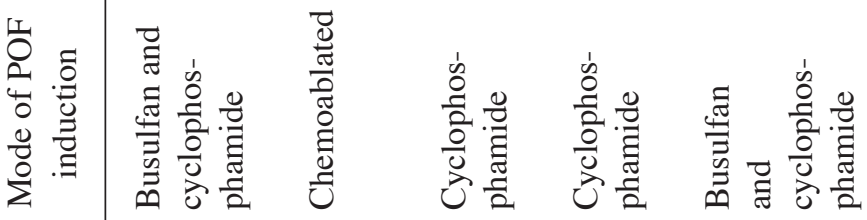

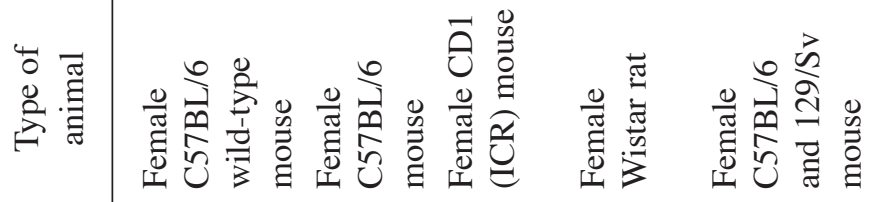

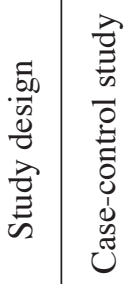

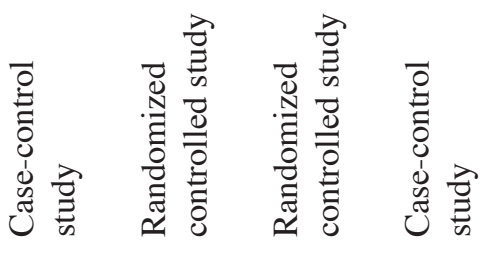

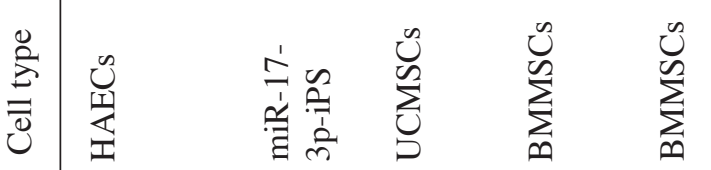

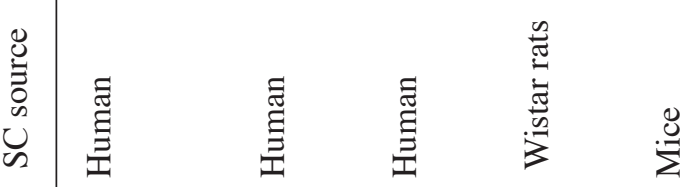

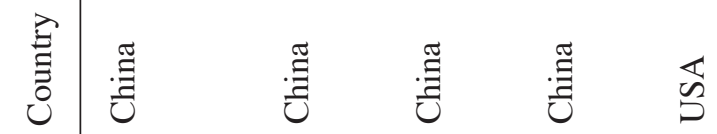

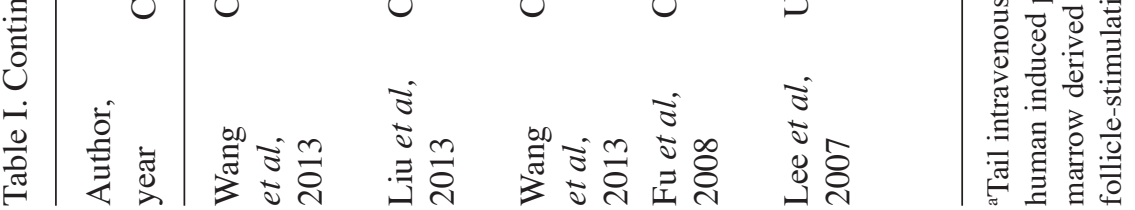




\begin{tabular}{|c|c|c|c|c|}
\hline $\begin{array}{l}\text { Study } \\
\text { ID }\end{array}$ & $\operatorname{SMD}(95 \% \mathrm{Cl})$ & $\begin{array}{c}\text { Stem cells } \\
\mathrm{N}, \text { mean }(\mathrm{SD})\end{array}$ & $\begin{array}{c}\text { Control } \\
\mathrm{N} \text {, mean }(\mathrm{SD}) \\
\end{array}$ & Weight\% \\
\hline Song D 2016-ITV & $-1.98(-3.76,-0.20)$ & $4,9.35(0.774)$ & $4,11(0.92)$ & 8.60 \\
\hline Song D 2016-in situ & $-1.91(-3.67,-0.16)$ & $4,9.49(0.67)$ & 4, $11(0.92)$ & 8.71 \\
\hline Elfayomy AK 2016 & $-2.00(-2.92,-1.07)$ & $16,5.8(1.2)$ & $12,10.7(3.5)$ & 13.07 \\
\hline Liu T 2016 & $-0.69(-1.42,0.05)$ & $15,436(713)$ & 15, $972(846)$ & 14.04 \\
\hline Dang J 2015 & $-2.87(-3.54,-2.20)$ & $35,1.95(0.276)$ & $35,2.9(0.378)$ & 14.36 \\
\hline Liu T 2014 & $-1.05(-1.82,-0.28)$ & $15,732(563)$ & $15,1545(940)$ & 13.90 \\
\hline Liu T 2013 & $-0.22(-1.20,0.76)$ & $8,620(50)$ & $8,630(40)$ & 12.75 \\
\hline Fu X 2008 & $-0.34(-0.97,0.28)$ & $20,8.6(6.53)$ & 20, 19.1 (42.9) & 14.58 \\
\hline $\begin{array}{l}\text { Overall }(I-\text { squared }=82.8 \%, P=0.001) \\
\text { Degrees of freedom }=7\end{array}$ & $-1.33(-2.09,-0.57)$ & 117 & 113 & 100.00 \\
\hline Note: weights are from random effects analysis & & & & \\
\hline-3.76 & 3.76 & & & \\
\hline
\end{tabular}

Figure 2. Forest plot demonstrating the effect of stem cell therapy on follicle stimulating hormone improvement compared with controls. SMD, standardized mean difference; $\mathrm{CI}$, confidence interval; SD, standard deviation; ITV, intra-tail venous.

\begin{tabular}{|c|c|c|c|c|}
\hline $\begin{array}{l}\text { Study } \\
\text { ID }\end{array}$ & $\operatorname{SMD}(95 \% \mathrm{Cl})$ & $\begin{array}{c}\text { Stem cells } \\
\mathrm{N}, \text { mean }(\mathrm{SD})\end{array}$ & $\begin{array}{c}\text { Control } \\
\mathrm{N}, \text { mean }(\mathrm{SD}) \\
\end{array}$ & Weight\% \\
\hline Song D 2016-ITV & $3.05(0.84,5.27)$ & $4,57.2(4.57)$ & $4,45.7(2.79)$ & 7.11 \\
\hline Song D 2016-in situ & $2.36(0.43,4.28)$ & $4,55.3(5.06)$ & $4,45.7(2.79)$ & 7.80 \\
\hline Elfayomy AK 2016 & $4.51(3.07,5.94)$ & $16,52(6.4)$ & $12,28.6(2.8)$ & 8.99 \\
\hline Su J 2016 & $0.70(-0.04,1.44)$ & $16,434(226)$ & $14,316(40.1)$ & 10.46 \\
\hline Liu T 2016 & $0.56(-0.17,1.29)$ & $15,159(163)$ & $15,87.4(73.6)$ & 10.47 \\
\hline Dang J 2015 & $4.99(4.03,5.95)$ & $35,12.6(1.42)$ & $35,6.73(0.842)$ & 10.05 \\
\hline Liu T 2014 & $1.62(0.79,2.46)$ & $15,323(131)$ & $15,136(96.7)$ & 10.29 \\
\hline Liu J 2014 & $6.59(3.13,10.05)$ & $5,53.2(3.01)$ & $5,36.1(2.11)$ & 4.68 \\
\hline Wang S 2013 & $1.05(0.29,1.82)$ & $15,112(52.6)$ & $15,66(32.7)$ & 10.41 \\
\hline Liu T 2013 & $2.63(1.25,4.01)$ & $8,162(4.62)$ & $8,151(4.28)$ & 9.12 \\
\hline Fu $\times 2008$ & $0.65(0.01,1.28)$ & $20,45(49.6)$ & $20,20.5(20.2)$ & 10.62 \\
\hline Overall $(I-$ squared $=90.0 \%, P=0.001)$ & $2.33(1.35,3.32)$ & 153 & 147 & 100.00 \\
\hline Degrees of freedom $=10$ & & & & \\
\hline Note: weights are from random effects analysis & & & & \\
\hline $\mathbf{- 1 0 . 1}^{\top}$ & $\begin{array}{c}10.1 \\
10.1\end{array}$ & & & \\
\hline
\end{tabular}

Figure 3. Forest plot presenting the effect of stem cell therapy on estradiol improvement compared with controls. SMD, standardized mean difference; CI, confidence interval; SD, standard deviation; ITV, intra-tail venous.

FSH $\left(I^{2}=82.8 \% ; \chi^{2}=40.79 ; \mathrm{P}<0.001\right), \mathrm{E} 2\left(\mathrm{I}^{2}=90.0 \% ; \chi^{2}=99.89 ;\right.$ $\mathrm{P}<0.001)$, ovarian weight $\left(\mathrm{I}^{2}=78.6 \% ; \chi^{2}=9.36 ; \mathrm{P}=0.009\right)$ and follicle count $\left(\mathrm{I}^{2}=90.0 \% ; \chi^{2}=310.53 ; \mathrm{P}<0.001\right)$.

Subgroup analyses and meta-regression. In order to investigate the source of the heterogeneity of the results, subgroup analyses of the included trails were performed based on study design, cell type, details of the animal model, different units of FSH, stages of the follicles and the route of stem cell delivery to assess their impact on the primary outcomes of
FSH, E2 and follicle count (Table II). For the amounts of stem cells delivered and the follow-up duration, a meta regression analysis was performed. Of note, the present study did not perform any subgroup analyses or meta regression for ovarian weight and the number of pregnancies based on the above baseline characteristics, as only 3-4 comparisons had been included. The results of the subgroup analyses or multivariate meta-regression demonstrated that study design, cell type, units of FSH, follicle stage, the follow-up duration, the route of delivery and amount of stem cells, as well as details of the 


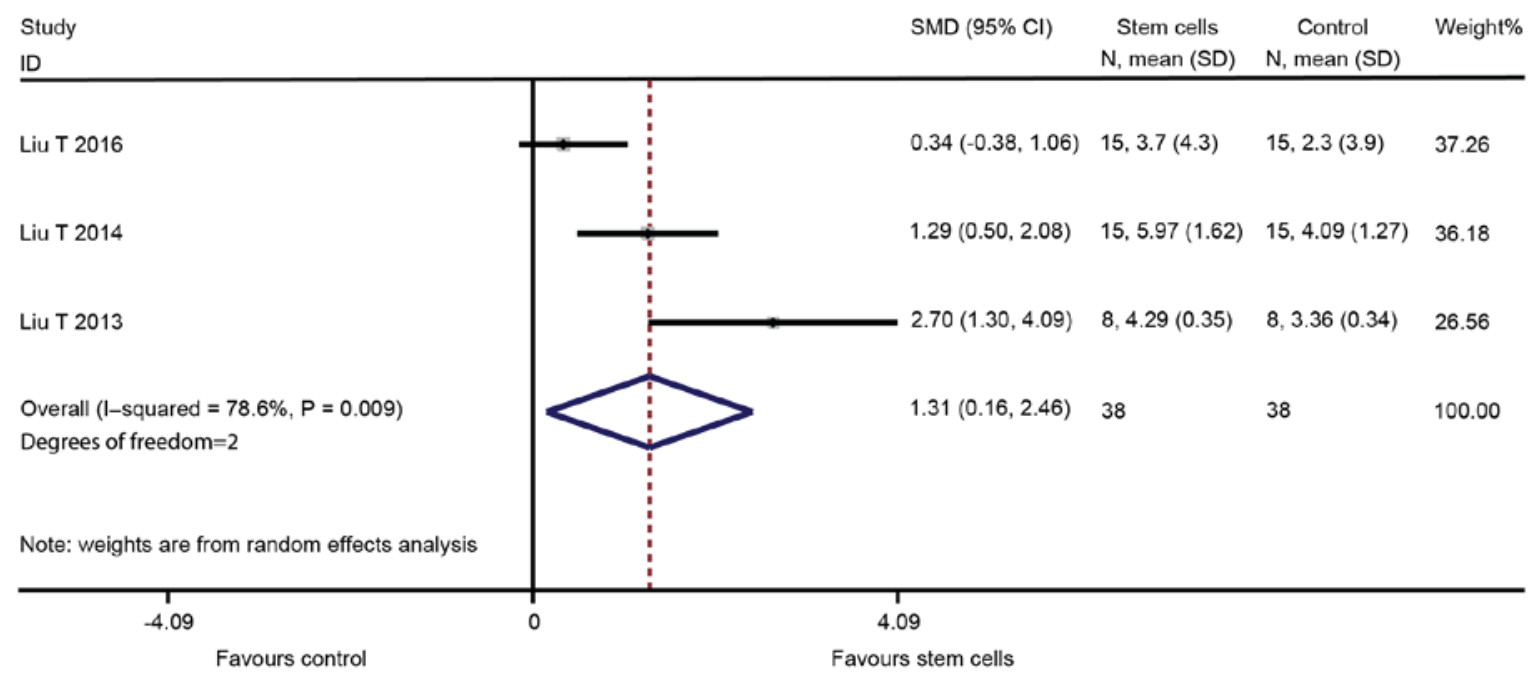

Figure 4. Forest plot presenting the effect of stem cell therapy on ovarian weight improvement compared with controls. SMD, standardized mean difference; $\mathrm{CI}$, confidence interval; SD, standard deviation; ITV, intra-tail venous.

\begin{tabular}{|c|c|c|c|c|}
\hline Overall $(1-$ squared $=90.0$ & SMD $(95 \% \mathrm{Cl})$ & $\begin{array}{c}\text { Stem cells } \\
\mathrm{N}, \text { mean }(\mathrm{SD})\end{array}$ & $\begin{array}{c}\text { Control } \\
\mathrm{N} \text {, mean }(\mathrm{SD})\end{array}$ & Weight\% \\
\hline Song D 2016-ITV-primordial & $0.53(-1.11,2.17)$ & $3,25.3(18)$ & $3,17.7(9.3)$ & 3.02 \\
\hline Song D 2016-in situ-primordial & $0.35(-1.27,1.97)$ & $3,20.7(7.8)$ & $3,17.7(9.3)$ & 3.04 \\
\hline Song D 2016-ITV-primary & $1.44(-0.44,3.33)$ & $3,11.7(5.5)$ & $3,6(1)$ & 2.84 \\
\hline Song D 2016-in situ-primary & $1.02(-0.73,2.76)$ & $3,8(2.6)$ & $3,6(1)$ & 2.94 \\
\hline Song D 2016-ITV-secondary & $4.26(0.90,7.61)$ & $3,6.7(1.2)$ & $3,2(1)$ & 1.86 \\
\hline Song D 2016-in situ-secondary & $2.87(0.32,5.42)$ & $3,6(1.7)$ & $3,2(1)$ & 2.37 \\
\hline Song D 2016-ITV-early antral & $0.81(-0.89,2.51)$ & $3,43(4.4)$ & $3,36(11.4)$ & 2.98 \\
\hline Song D 2016-in situ-early antral & $1.83(-0.21,3.88)$ & $3,52.7(6)$ & $3,36(11.4)$ & 2.73 \\
\hline Su J 2016-antral & $2.68(1.67,3.68)$ & $16,139(23.8)$ & $14,76(23.2)$ & 3.44 \\
\hline Elfayomy AK 2016-antral & $3.29(2.13,4.46)$ & $16,7.3(1.6)$ & $12,2.3(1.4)$ & 3.34 \\
\hline Liu T 2016-atretic & $-0.65(-1.38,0.09)$ & $15,4(7.7)$ & $15,9(7.7)$ & 3.58 \\
\hline Zhang Q 2015-primordial & $0.14(-0.99,1.28)$ & $6,36(21.1)$ & $6.33 .1(19.4)$ & 3.37 \\
\hline Zhang Q 2015-primary & $0.00(-1.13,1.13)$ & $6,28.8(14.1)$ & $6,28.8(12.3)$ & 3.37 \\
\hline Zhang Q 2015-secondary & $1.67(0.32,3.02)$ & $6,20.9(8.82)$ & $6,7.19(7.5)$ & 3.23 \\
\hline Zhang Q 2015-atretic & $-8.26(-12.05,-4.47)$ & $6,25.9(7.05)$ & $6,137(17.6)$ & 1.63 \\
\hline Zhang Q 2015-mature & $0.28(-0.86,1.42)$ & $6,2.88(7.05)$ & $6,1.44(1.76)$ & 3.36 \\
\hline Dang J 2015-primordial & $7.98(6.56,9.40)$ & $35,750(67.1)$ & $35,326(34.1)$ & 3.18 \\
\hline Kilic S 2014-primordial and primary & $2.83(1.47,4.20)$ & $11,4(0.77)$ & $7,1.9(0.69)$ & 3.22 \\
\hline Kilic S 2014-preantral & $1.03(0.01,2.04)$ & $11,3.9(0.83)$ & 7. $3.1(0.69)$ & 3.44 \\
\hline Kilic S 2014-antral & $3.49(1.95,5.03)$ & $11,6.5(0.82)$ & $7,3.8(0.69)$ & 3.10 \\
\hline Kilic S 2014-total number of follicles & $3.93(2.27,5.59)$ & $11,17(1.41)$ & $7,12(1)$ & 3.01 \\
\hline Liu J-2014-antral & $2.23(0.58,3.89)$ & $5,5.6(1.14)$ & $5,2.6(1.52)$ & 3.01 \\
\hline Wang F 2013-primordial & $2.17(1.32,3.02)$ & $20,69.6(37.5)$ & $15,7.14(7.15)$ & 3.53 \\
\hline Wang F 2013-primary & $5.12(3.72,6.53)$ & $20,84.6(10.9)$ & $15,15.4(16.4)$ & 3.19 \\
\hline Wang F 2013-secondary & $5.92(4.34,7.49)$ & $20,54.5(8.95)$ & $15,12.7(2.98)$ & 73.0 \\
\hline Wang F 2013-atretic & $1.32(0.58,2.06)$ & $20,95.6(31.1)$ & $15,40(53.3)$ & 3.58 \\
\hline Wang S 2013-total number of follicles & $4.92(3.44,6.39)$ & $15,108(15)$ & $15,39(13)$ & 3.14 \\
\hline Fu X-2008-primordial & $0.47(-0.16,1.10)$ & $20,398(82.2)$ & $20,347(128)$ & 3.63 \\
\hline Fu X-2008-primary & $0.42(-0.20,1.05)$ & $20,125(65.7)$ & $20,99.1(57.2)$ & 3.63 \\
\hline Fu X-2008-secondary & $0.45(-0.18,1.08)$ & $20,51.9(50.6)$ & $20,33.2(30.4)$ & 3.63 \\
\hline Fu X-2008-antral & $0.87(0.22,1.52)$ & $20,58.7(27)$ & $20,37.4(21.9)$ & 3.62 \\
\hline Lee $\mathrm{HJ}-2007$-immature & $2.17(0.43,3.91)$ & $5,369(199)$ & $4,41(24)$ & 2.95 \\
\hline $\begin{array}{l}\text { Overall (I-squared }=90.0 \%, \mathrm{P}<0.001) \\
\text { Degrees of freedom }=31 \\
\text { Note: } \text { weights are from random effects analysis }\end{array}$ & $1.87(1.23,2.52)$ & 365 & 322 & 100.00 \\
\hline (1) & $T$ & & & \\
\hline-12.1 & 12.1 & & & \\
\hline Favours control & Favours stem cells & & & \\
\hline
\end{tabular}

Figure 5. Forest plot illustrating the effect of stem cell therapy on follicles count improvement compared with controls. SMD, standardized mean difference; CI, confidence interval; SD, standard deviation; ITV, intra-tail venous.

animal model, were not the cause of the heterogeneity of the results on FSH, E2 and follicle count in animal models of POF treated with stem cells.

Sensitivity analyses and publication bias. To evaluate the robustness of the estimated pooled effect size for FSH, E2, ovarian weight, follicle count and the number of pregnancies, the present study performed a sensitivity analysis by sequentially excluding one study at a time and recalculating the pooled effect size of the remaining studies. The results of sensitivity analyses revealed that none of the individual studies appeared to impact the overall results on FSH, E2, ovarian weight, follicle count and the number of pregnancies in animal models of POF based on the stem cell therapy, which suggested that the pooled effect on FSH, E2, ovarian weight, follicle count and the number of pregnancies was stable (data not shown). 


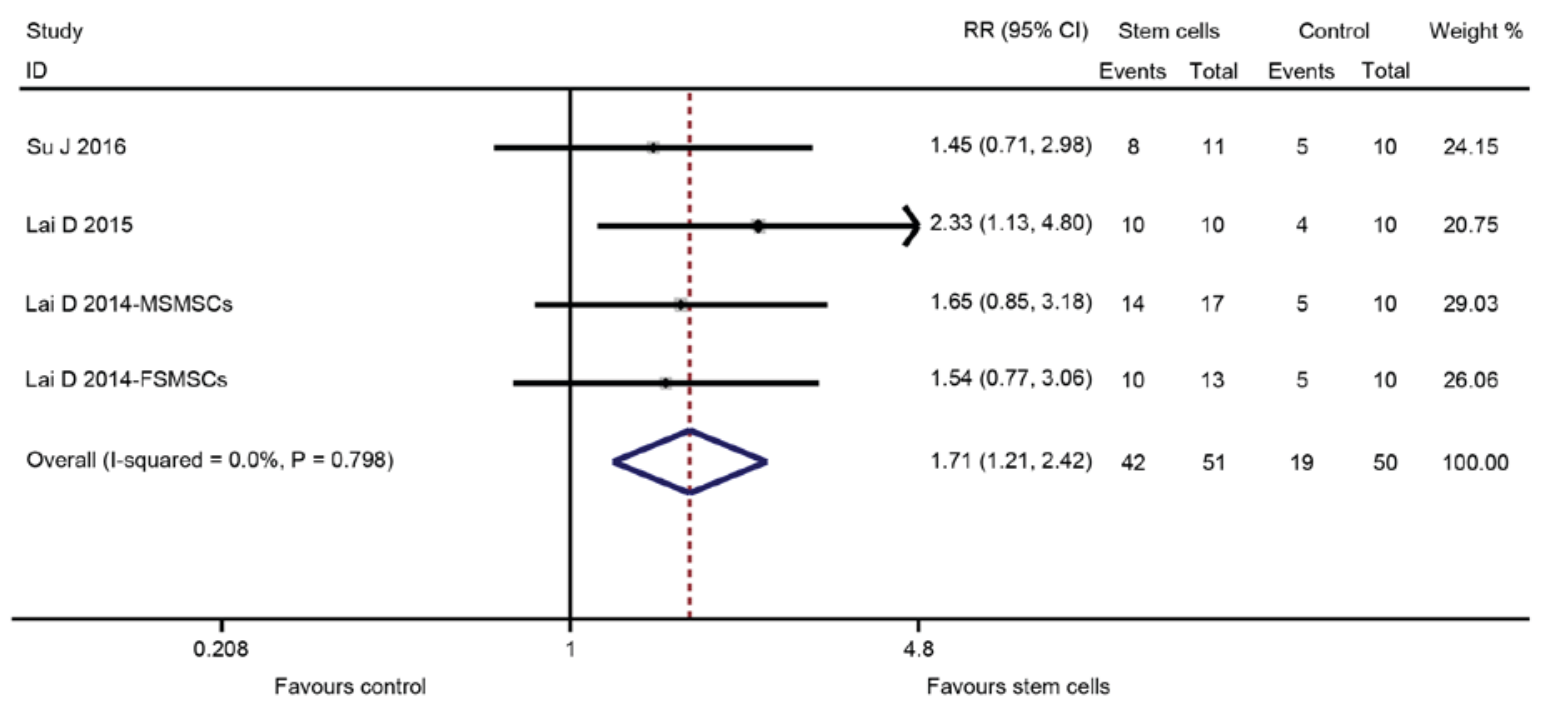

Figure 6. Forest plot presenting the effect of stem cell therapy on the number of pregnancy improvement compared with controls. RR, risk ratio; CI, confidence interval; SD, standard deviation; ITV, intra-tail venous.

The funnel plots for the effects of stem cell therapy on E2 and follicle count were asymmetrical on visual inspection, indicating that possible publication bias may have existed between the eligible studies (Figs. 7 and 8, respectively). Consistently, the results of Egger's and Begg's tests also demonstrated the existence of potential publication bias (for $\mathrm{E} 2, \mathrm{P}=0.039$ and 0.008 for Egger's and Begg's test, respectively; for follicle count, $\mathrm{P}=0.028$ and 0.046 for Egger's and Begg's test, respectively). Subsequently, a 'trim-and-fill' analysis was performed by imputing five and nine hypothetical negative unpublished studies for E2 and follicle count, respectively, with the aim of producing a symmetrical funnel plot. The pooled effect size including the hypothetical studies under the random-effects model remained statistically significant in favor of stem cells for E2 (16 comparisons; SMD=2.71; 95\% CI, 0.90-8.21) and follicle count (41 comparisons; $\mathrm{SMD}=2.27$; 95\% CI, 1.10-4.69). In addition, no potential publication bias was noted for FSH based on visual inspection of the funnel plot (Fig. 9), which was consistent with the results of Egger's test $(\mathrm{P}=0.760)$ and Begg's test $(\mathrm{P}=0.536)$. However, the publication bias among studies on the effects of stem cell therapy on ovarian weight and the number of pregnancies were difficult to assess, as only three to four studies were available for each comparison.

Case report results. After MSC treatment, TVS and TAS imaging indicated that the size of the ovaries and the endometrial thickness were improved. On March 6, 2014, the sizes of the left and right ovary were $1.9 \times 1.3$ and $2.2 \times 1.0 \mathrm{~cm}$, respectively. On May 15, 2014, the sizes of the left and right ovary were $2.3 \times 1.6$ and $2.3 \times 1.9 \mathrm{~cm}$, respectively. On July 24,2014 , the sizes of the left and right ovary were $3.3 \times 2.0$ and $2.7 \times 1.2 \mathrm{~cm}$, respectively. The endometrial thickness was $0.3,0.6$ and $0.75 \mathrm{~cm}$ on March 6, May 15, and July 24, 2014, respectively. No abnormal echo was found in the parenchyma. Of note, the results of CDFI on July 24, 2014 suggested abundant blood flow signals in the patient's uterus. Endometrial morphology and size of ovary on March 6 and May 15, 2014 are presented in Figs. 10 and 11, respectively. Endometrial morphology and blood flow on July 24, 2014 are presented in Fig. 12.

\section{Discussion}

The etiology of POF is complex and may be caused by numerous factors, such as genetic defects, autoimmune reactions, chemotherapy, radiotherapy and surgery. At present, no effective treatment for POF is currently available. Stem cells, as a multipotent cell type with the capacity of self-renewal and multilineage differentiation, have been proposed as a promising tool in tissue engineering for regenerative medicine (37). Their therapeutic potential has provided a novel strategy for preserving or recovering damaged ovarian function of women who receive chemotherapy or radiotherapy. Previous studies on animal models have revealed a favorable effect of stem cell-based therapy on POF caused by chemotherapy, radiotherapy or other etiologies $(25,26)$. However, to the best of our knowledge, those studies lack quantitative evaluation of the results and no randomized controlled trial in humans has currently been published. Therefore, a meta-analysis of animal studies was performed to assess the effects of stem cell therapy for POF and to describe the case report in the present study.

In the present meta-analysis, FSH, E2, follicle count, ovary weight and the number of pregnancies were selected as the outcome of interest, as they are known to correlate well with ovarian function recovery after POF, and are considered as reliable predictors for the risk of POF in women $(38,39)$. The observed improvement of FSH, E2, follicle count, ovary weight and the number of pregnancies after stem cell transplantation strongly indicated a favorable therapeutic effect of stem cells on POF. Specifically, the result of the present meta-analysis indicated that stem cell transplantation was associated with a significant improvement of ovarian function in animal models of POF, by improving the weight of ovaries, restoring fertility and the number of pregnancies and balancing the level of serum sex hormones (FSH and E2), which demonstrated the potential of stem cell-based therapies for treating POF. These improvements may be attributed to the differentiation, homing and paracrine function of stem cells. The proposed mechanisms via which stem cells repair the damaged ovarian function in POF include the following: i) Stem cells migrate into injured 
Table II. Subgroup analyses and meta regression for the effects of stem-cell based therapy on FSH, E2 and follicle counts in animal models of POF.

\begin{tabular}{|c|c|c|c|c|c|}
\hline Index/subgroup & Studies (n) & $\begin{array}{l}\text { SMD/RR } \\
(95 \% \mathrm{CI})\end{array}$ & $\begin{array}{l}\text { P-value for subgroup } \\
\text { outcomes/interactions }\end{array}$ & $\mathrm{I}^{2}(\%)$ & $\begin{array}{l}\text { Heterogene } \\
\text { P-value }\end{array}$ \\
\hline \multicolumn{6}{|l|}{ FSH } \\
\hline \multicolumn{6}{|l|}{ Delivery method } \\
\hline ITV & 1 & $-1.98(-3.76,-0.20)$ & 0.029 & - & - \\
\hline Non-ITV & 7 & $-1.27(-2.09,-0.45)$ & 0.002 & 85.1 & 0.000 \\
\hline \multicolumn{6}{|c|}{ Follow-up duration } \\
\hline Per week & 8 & $1.22(1.18,8.34)$ & 0.805 & 84.7 & \\
\hline \multicolumn{6}{|l|}{ Cell amount } \\
\hline Per $1 \times 10^{6}$ & 8 & $1.47(0.21,10.1)$ & 0.640 & 85.1 & \\
\hline \multicolumn{6}{|l|}{ Units } \\
\hline IU/1 & 6 & $-1.65(-2.60,-0.70)$ & 0.001 & 84.4 & 0.000 \\
\hline $\mathrm{pg} / \mathrm{ml}$ & 2 & $-0.52(-1.11,0.07)$ & 0.085 & 0.0 & 0.459 \\
\hline \multicolumn{6}{|c|}{ Details of the animal model } \\
\hline Chemotherapy & 7 & $-0.989(-1.526,-0.452)$ & 0.000 & 55.3 & 0.037 \\
\hline Radiotherapy & 1 & $-2.867(-3.540,-2.195)$ & 0.000 & - & - \\
\hline \multicolumn{6}{|l|}{ Study design } \\
\hline Case control & 6 & $-1.149(-1.735,-0.562)$ & 0.000 & 48.3 & 0.085 \\
\hline $\mathrm{RCT}$ & 2 & $-1.602(-4.076,0.873)$ & 0.205 & 96.6 & 0.000 \\
\hline \multicolumn{6}{|l|}{ Cell type } \\
\hline UCMSCs & 3 & $-1.980(-2.724,-1.236)$ & 0.000 & 0.0 & 0.997 \\
\hline OGLCs-iPSCs & 1 & $-0.685(-1.423,0.053)$ & 0.069 & - & - \\
\hline HCMNCs & 1 & $-2.867(-3.540,-2.195)$ & 0.000 & - & - \\
\hline EnSCs & 1 & $-1.049(-1.815,-0.282)$ & 0.007 & - & - \\
\hline miR-17-3p-iPS & 1 & $-0.221(-1.204,0.763)$ & 0.660 & - & - \\
\hline BMMSCs & 1 & $-0.342(-0.967,0.282)$ & 0.283 & - & - \\
\hline \multicolumn{6}{|l|}{ Stem cell origin } \\
\hline Human & 7 & $-1.498(-2.308,-0.687)$ & 0.000 & 80.0 & 0.000 \\
\hline Rat & 1 & $-0.342(-0.967,0.282)$ & 0.283 & - & \\
\hline \multicolumn{6}{|l|}{ E2 } \\
\hline \multicolumn{6}{|l|}{ Delivery method } \\
\hline ITV & 3 & $3.15(0.34,5.95)$ & 0.028 & 82.6 & 0.003 \\
\hline Non-ITV & 8 & $2.19(1.01,3.37)$ & 0.000 & 92.1 & 0.000 \\
\hline \multicolumn{6}{|c|}{ Follow-up duration } \\
\hline Per week & 11 & $0.76(0.04,12.95)$ & 0.831 & 91.0 & \\
\hline \multicolumn{6}{|l|}{ Cell amount } \\
\hline Per $1 \times 10^{6}$ & 11 & $1.01(0.06,16.56)$ & 0.991 & 90.8 & \\
\hline \multicolumn{6}{|c|}{ Details of the animal model } \\
\hline Chemotherapy & 10 & $1.877(1.112,2.643)$ & 0.000 & 80.7 & 0.000 \\
\hline Radiotherapy & 1 & $4.990(4.029,5.951)$ & 0.000 & - & - \\
\hline \multicolumn{6}{|l|}{ Study design } \\
\hline Case control & 7 & $2.689(1.439,3.939)$ & 0.000 & 82.9 & 0.000 \\
\hline $\mathrm{RCT}$ & 4 & $1.822(0.072,3.573)$ & 0.041 & 95.3 & 0.000 \\
\hline \multicolumn{6}{|l|}{ Cell type } \\
\hline UCMSCs & 4 & $2.683(0.853,4.514)$ & 0.004 & 83.8 & 0.000 \\
\hline ADSCs & 1 & $0.704(-0.037,1.444)$ & 0.063 & - & - \\
\hline OGLCs-iPSCs & 1 & $0.561(-0.169,1.292)$ & 0.132 & - & - \\
\hline HCMNCs & 1 & $4.990(4.029,5.951)$ & 0 & - & - \\
\hline EnSCs & 1 & $1.624(0.791,2.456)$ & 0 & - & - \\
\hline BMMSCs & 2 & $3.367(-2.439,9.174)$ & 0.256 & 90.9 & 0.001 \\
\hline miR-17-3p-iPS & 1 & $2.630(1.248,4.011)$ & 0 & - & \\
\hline \multicolumn{6}{|l|}{ Stem cell origin } \\
\hline Human & 8 & $2.546(0.310,3.782)$ & 0 & 90.3 & 0.000 \\
\hline Rat & 3 & $1.410(-0.002,2.822)$ & 0.05 & 81.9 & 0.004 \\
\hline
\end{tabular}


Table II. Continued.

\begin{tabular}{|c|c|c|c|c|c|}
\hline Index/subgroup & Studies (n) & $\begin{array}{l}\text { SMD/RR } \\
(95 \% \mathrm{CI})\end{array}$ & $\begin{array}{l}\text { P-value for subgroup } \\
\text { outcomes/interactions }\end{array}$ & $\mathrm{I}^{2}(\%)$ & $\begin{array}{l}\text { Heterogeneity } \\
\text { P-value }\end{array}$ \\
\hline \multicolumn{6}{|l|}{ Follicle count } \\
\hline \multicolumn{6}{|l|}{ Delivery method } \\
\hline ITV & 16 & $1.747(0.749,2.744)$ & 0.001 & 88.0 & 0.000 \\
\hline Non-ITV & 16 & $1.968(1.097,2.840)$ & 0 & 91.6 & 0.000 \\
\hline \multicolumn{6}{|l|}{ Follow-up duration } \\
\hline Per week & 32 & $0.93(0.15,5.73)$ & 0.938 & 90.2 & \\
\hline \multicolumn{6}{|l|}{ Cell amount } \\
\hline Per $1 \times 10^{6}$ & 32 & $1.09(0.14,8.48)$ & 0.933 & 90.3 & \\
\hline \multicolumn{6}{|l|}{ Details of the animal model } \\
\hline Chemotherapy & 31 & $1.670(1.101,2.240)$ & 0 & 86.7 & 0.000 \\
\hline Radiotherapy & 1 & $7.977(6.557,9.397)$ & 0 & - & - \\
\hline \multicolumn{6}{|l|}{ Study design } \\
\hline Case control & 21 & $1.489(0.671,2.308)$ & 0 & 86.7 & 0.000 \\
\hline $\mathrm{RCT}$ & 11 & $2.530(1.420,3.640)$ & 0 & 93.8 & 0.000 \\
\hline \multicolumn{6}{|l|}{ Cell type } \\
\hline UCMSCs & 10 & $2.056(0.989,3.123)$ & 0 & 72.0 & 0.000 \\
\hline ADSCs & 1 & $2.678(1.675,3.681)$ & 0 & - & - \\
\hline OGLCs-iPSCs & 1 & $-0.649(-1.385,0.086)$ & 0.084 & - & - \\
\hline HAECs & 9 & $1.349(-0.055,2.753)$ & 0.06 & 92.0 & 0.000 \\
\hline HCMNCs & 1 & $7.977(6.557,9.397)$ & 0 & - & - \\
\hline BMMSCs & 10 & $1.532(0.876,2.188)$ & 0 & 78.5 & 0.000 \\
\hline \multicolumn{6}{|l|}{ Stem cell origin } \\
\hline Human & 21 & $1.884(0.852,2.916)$ & 0 & 92.0 & 0.000 \\
\hline Rat & 10 & $1.634(0.943,2.325)$ & 0 & 82.3 & 0.000 \\
\hline Mouse & 1 & $2.169(0.431,3.906)$ & 0.014 & - & - \\
\hline \multicolumn{6}{|l|}{ Follicle stage } \\
\hline Primordial & 6 & $1.93(-0.06,3.92)$ & 0.057 & 95.1 & 0.000 \\
\hline Primary & 5 & $1.57(-0.16,3.92)$ & 0.075 & 89.9 & 0.000 \\
\hline Secondary & 5 & $2.91(0.64,5.71)$ & 0.012 & 91.0 & 0.000 \\
\hline Antral & 7 & $2.17(1.23,3.10)$ & 0 & 74.3 & 0.000 \\
\hline Atretic & 3 & $-1.50(-4.06,1.05)$ & 0.248 & 93.9 & 0.000 \\
\hline Total follicles & 2 & $4.48(3.38,5.58)$ & 0 & 0 & 0.384 \\
\hline Mature & 1 & $0.28(-0.86,1.42)$ & 0.629 & - & - \\
\hline Preantral & 1 & $1.03(0.01,2.04)$ & 0.047 & - & - \\
\hline Primordial and primary & 1 & $2.83(1.47,4.20)$ & 0 & - & - \\
\hline Immature & 1 & $2.17(0.43,3.91)$ & 0.014 & - & - \\
\hline
\end{tabular}

ITV, intra-tail venous; RCT, randomized controlled trial; UCMSCs, human umbilical cord mesenchymal stem cells; ADSCs, adipose-derived stem cells; OGLCs-iPSCs, ovarian granulosa-like cells derived from human induced pluripotent stem cells; HAECs, human amniotic epithelial cells; HCMNCs, human cord blood mononuclear cells; EnSCs, human endometrial mesenchymal stem cells; BMMSCs, bone marrow derived mesenchymal stem cells; miR-17-3p-iPS, microRNA-17-3p-transfected human-induced pluripotent stem cells; SMD, standard mean difference; CI, confidence interval; RR, risk ratios.

ovarian tissue and differentiate into ovarian tissue-like cells, particularly into granulosa cells, which are an essential component of the ovarian micro-environment and have a key role in regulating reproductive ovarian physiology, including ovulation and luteal regression (25); ii) stem cells may home to and reside in ovarian tissue and help to improve the damaged ovarian niches by secreting a number of angiogenic growth factors, such as hepatocyte growth factor, vascular endothelial grow th factor, placental growth factor and transforming growth factor- $\beta(23,40)$; and iii) stem cell transplantation effectively alleviates the chemotherapy-induced inflammatory reaction in ovarian tissue via secretion of anti-inflammatory factors (25). These mechanisms support that stem cell therapy is beneficial for the improvement of ovarian function in subjects with POF.

In spite of stem cell therapy having been identified to have significant beneficial pooled effects on each outcome measure, a considerable degree of heterogeneity was observed in the estimates of the present study. Thus, subgroup analyses and 


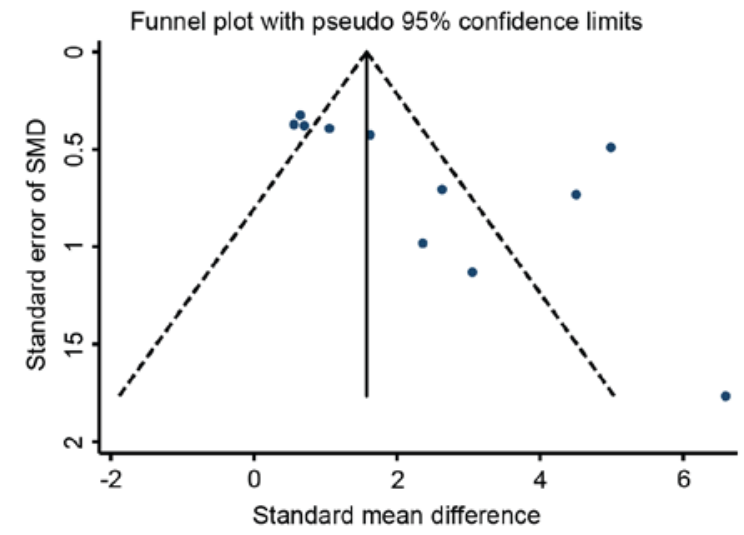

Figure 7. Funnel plot of the SMD for estradiol in animal models of premature ovarian failure assigned to the stem cell-based therapy or control groups. SMD, standardized mean difference.

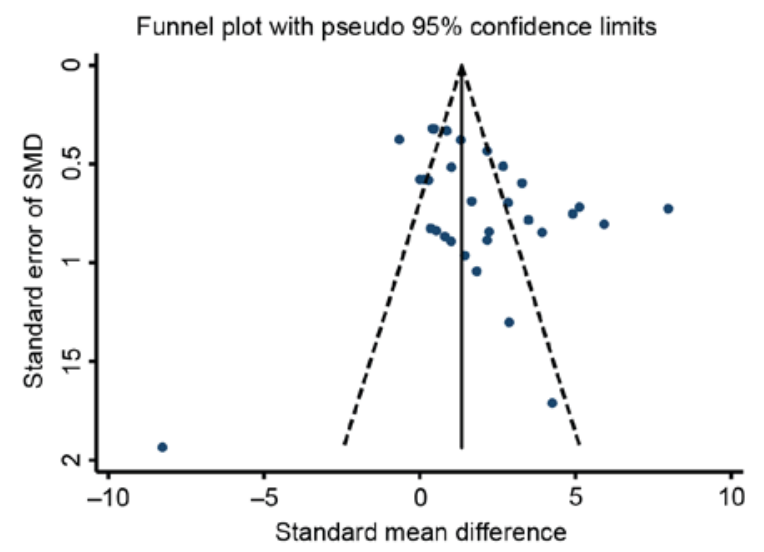

Figure 8. Funnel plot of the SMD for follicle count of premature ovarian failure in animal models of premature ovarian failure assigned to the stem cell-based therapy or control groups. SMD, standardized mean difference.

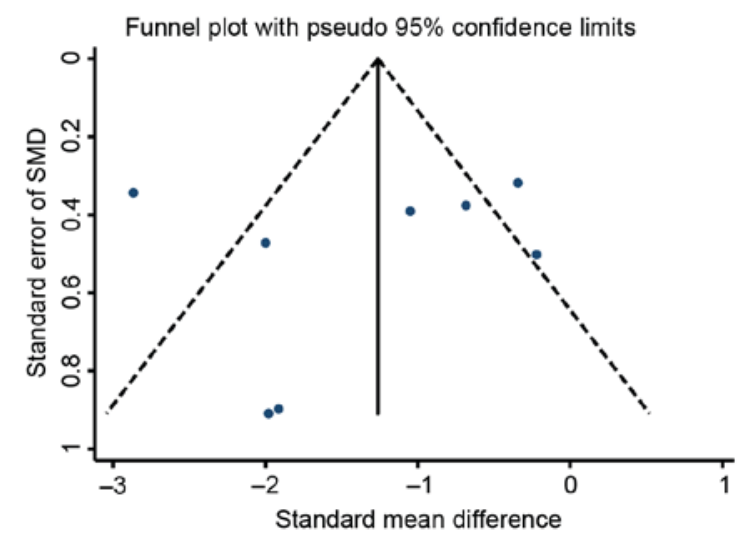

Figure 9. Funnel plot of the SMD for follicle-stimulating hormone in animal models of premature ovarian failure assigned to the stem cell-based therapy or control groups. SMD, standardized mean difference.

meta regression were performed to estimate potential sources of the heterogeneity. Based on this analysis, it was found that study design, cell type, different units of FSH, stage of the follicles, details of the animal models, the amount and route of administration of stem cells and the follow-up duration were not the causes of the heterogeneity of the results for FSH,
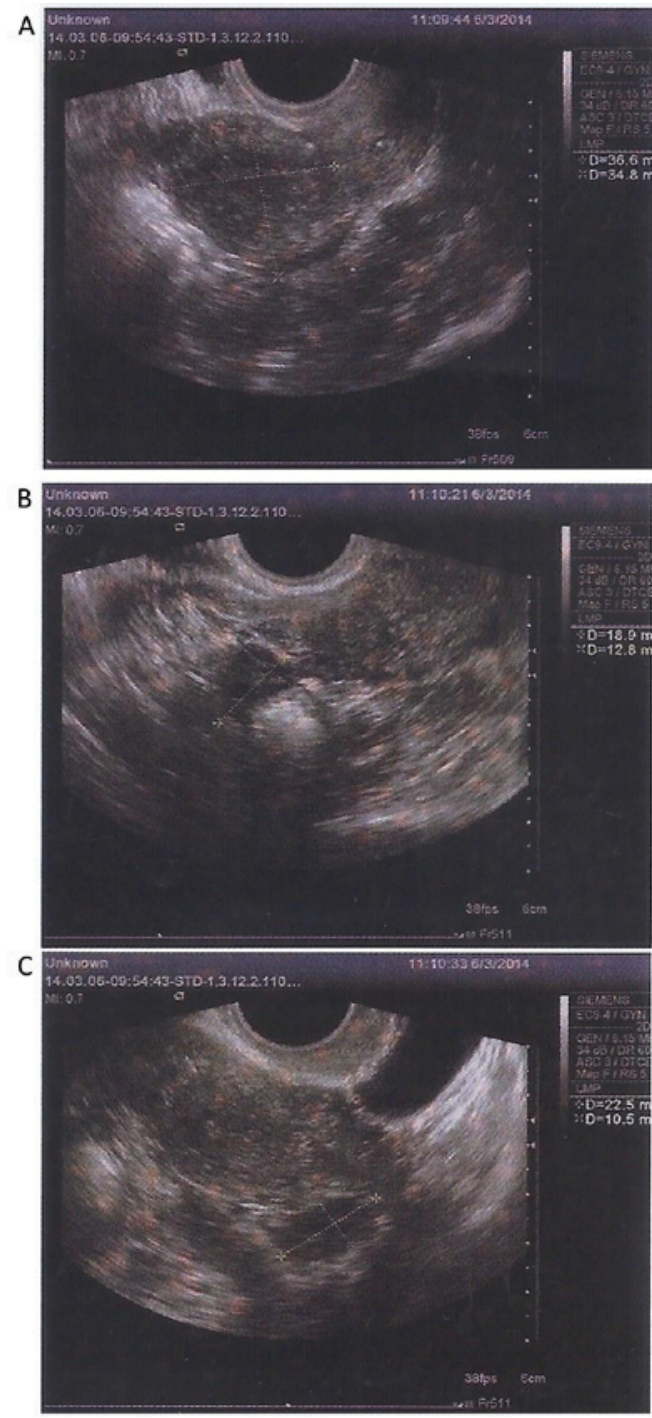

Figure 10. Transabdominal ultrasound and transvaginal ultrasound detection of endometrial morphology on March 6, 2014. The (A) endometrial thickness was $0.3 \mathrm{~cm}$ and, sizes of (B) right and (C) left ovary were $2.2 \times 1.0$ and $1.9 \times 1.3 \mathrm{~cm}$, respectively.

E2 and follicle count. Of note, however, among the 16 trails included, only one study assessed stem cell therapy in animal models of POF induced by radiotherapy, while all others used animals of POF induced by chemotherapy. Therefore, there may be a non-negligible difference in the therapeutic effects of POF between chemotherapy and radiotherapy, and further research is required to confirm this observation. In addition, studies have demonstrated that the degree of ovarian damage induced by chemotherapy and radiotherapy is dependent on factors such as the dose, drug type, patient age and the radiation therapy field $(39,41,42)$. Among the studies included in the present meta-analysis, the dose of chemotherapeutic drugs or radiation dose, drug type, as well as the age of the animals were different in each study. In addition, to date, it has remained to be determined which specific approach of assessing the therapeutic effect of stem cell-based therapy on POF induced is most favorable with regard to induction by chemotherapy or radiotherapy. Therefore, although the effect of stem cells in the treatment of POF was systematically evaluated by the present study, certain potential limitations 
A

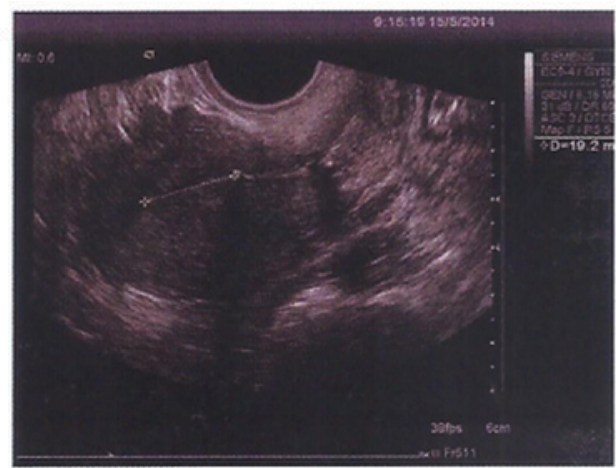

B

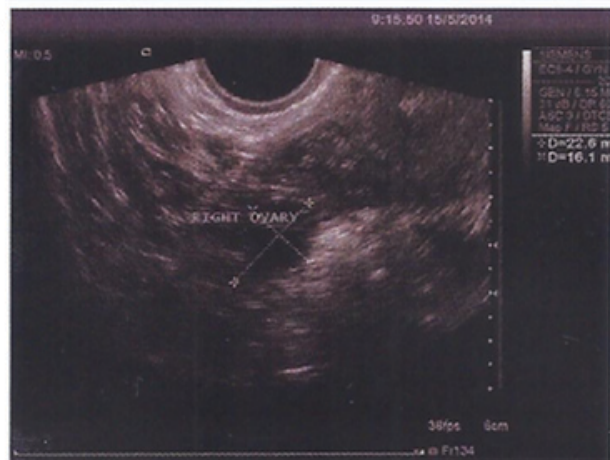

C

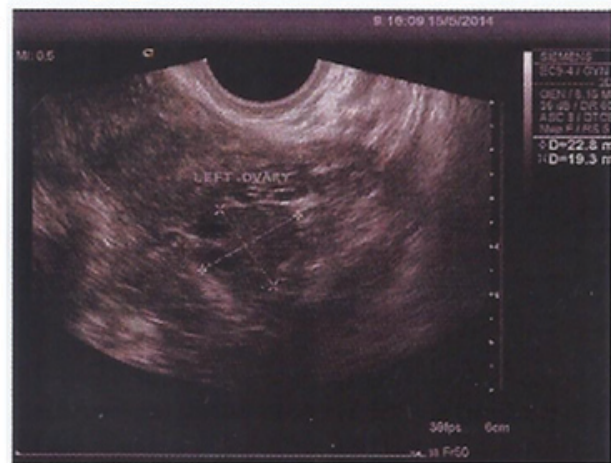

Figure 11. Transabdominal ultrasound and transvaginal ultrasound detection of endometrial morphology on May 15, 2014. (A) The endometrial thickness was $0.6 \mathrm{~cm}$. The sizes of (B) right and (C) left ovary were $2.3 \times 1.9$ and $2.3 \times 1.6 \mathrm{~cm}$, respectively.

remained, which should be considered when interpreting the results. First, the present study confirmed that stem cell-based therapy effectively improves ovarian function in animal models of POF through reducing the levels of FSH, elevating the levels of E2, restoring the fertility of animals, as well as promoting the formation of follicles, but the significant heterogeneity among the included studies should be considered. Furthermore, although subgroup analyses and meta regression suggested that the abovementioned baseline characteristics were not the causes of heterogeneity, the heterogeneity may have been due to the limited number of studies included for each outcome. Hence, large-scale studies based on the above classification features are required in the future. In addition, FSH, E2, ovary weight, follicle count and the number of pregnancies were selected as the outcomes of interest, but whether stem cell-based therapy confers other benefits, such as improvement in the estrous cycle of animals or LH, remains elusive and deserves further study. Furthermore, few studies have considered measuring ovary weight, and it was therefore not possible to determine the heterogeneity of
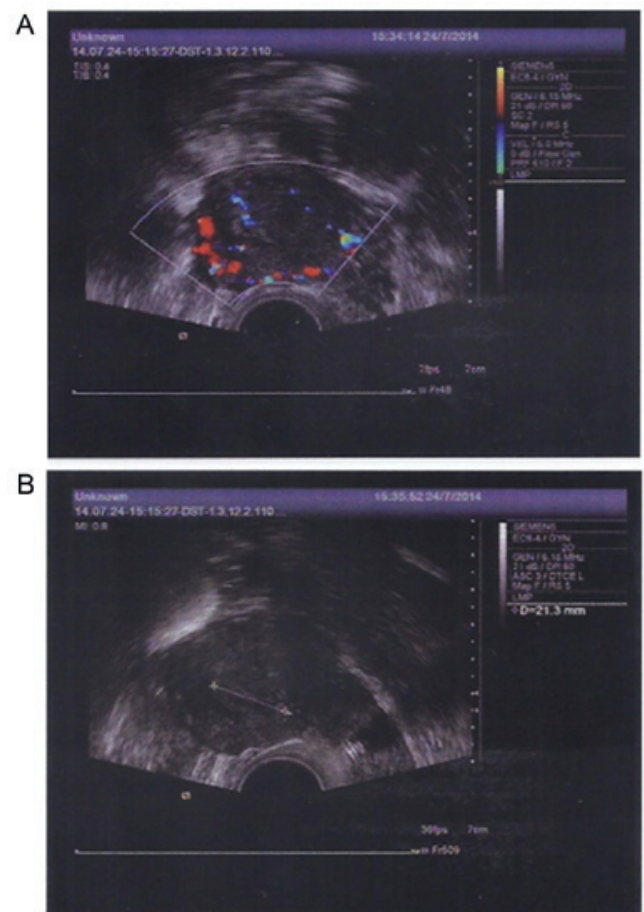

Figure 12. Transvaginal color Doppler flow imaging and transabdominal ultrasound detection of endometrial morphology on July, 242014 (A) Abundant blood flow signals in the endometrium were detected. The sizes of the left and right ovary were $3.3 \times 2.0$ and $2.7 \times 1.2 \mathrm{~cm}$, respectively. (B) Endometrial thickness was $0.75 \mathrm{~cm}$.

the results of ovarian weight. Therefore, future large-scale, high-quality studies are required to determine what causes the heterogeneity of the results of ovarian weight. In addition, a great variety of stem cell types were included, and the therapeutic effect of stem cells from different sources in POF may be different; therefore, their influence on the accuracy of the results cannot be ignored. Finally, indications of publication bias were identified, which may have impacted the results of the present meta-analysis; this is a common phenomenon that usually affects meta-analyses of animal studies, as those studies with positive results are more likely to be published. In view of this problem, the present study performed a 'trim and fill' procedure via hypothetically imputing unpublished studies with negative results. It was found that the pooled results were not significantly influenced by the publication bias based on 'trim and fill' analysis.

Of note, stem cell-based therapy is also capable of improving the ovarian function of the patient with POF who was the subject of the present case report. After MSC therapy, the sizes of the ovaries returned to normal and the endometrial thickness was increased, along with rich endometrial blood flow, suggesting that stem cell therapy may be an effective therapeutic strategy for the treatment of POF. However, regarding the case study of the present study, certain limitations require discussing. First, the patient was not monitored for folliculogenesis by B ultrasound. Furthermore, the ovarian function was not further evaluated through the detection of serum hormone levels (FSH, E2, LH). In addition, the participant was not followed up long-term to observe the recovery of menstruation. Therefore, further and deeper investigation is required to better confirm the efficacy of stem cell transplantation in patients with 
POF. The present case report was a study of level 4 evidence according to evidence-based medicine (43), but the results were positive; furthermore, a prospective study has reported that stem cell transplantation not only resulted in improvement of the hormonal profile of a POF patient but also in the resuming of menstruation and the occurrence of pregnancy, resulting in the delivery of a full-term healthy infant (10). This result was indicative of a good clinical outcome. For this reason, clinical randomized controlled trial studies are required in the future.

In conclusion, the results of the present meta-analysis illustrated that stem cell transplantation into animal models of POF significantly improved the ovarian function as compared with that of untreated controls. These results combined with the present case report demonstrated that stem cell-based strategies may become a potential therapy for POF.

\section{Acknowledgements}

The authors would like to thank Mr. Tao Tan (TRIM-edicine, Inc., Columbus, $\mathrm{OH}$, USA) for the help with the modification of this manuscript.

\section{Funding}

No funding was received.

\section{Availability of data and materials}

All data generated or analyzed during this study are included in this published articles.

\section{Authors' contributions}

LC was a major contributor in writing the manuscript. YX and SG conceived and designed the study. LC, CW and HL analyzed the data. HW contributed in the aquisition of data and edited the figures. All authors read and approved the final manuscript.

\section{Ethics approval and consent to participate}

The case report in the present study was performed with the informed consent of the patient according to the Declaration of Helsinki and was approved by the Society of Medical Ethics of Jiangsu Province (Nanjing, China).

\section{Consent for publication}

The patient agreed for ultrasound and scanning images to be published in the present study.

\section{Competing interests}

The authors declare that they have no competing interests.

\section{References}

1. Robles A, Checa MA, Prat M and Carreras R: Medical alternatives to oocyte donation in women with premature ovarian failure: A systematic review. Gynecol Endocrinol 29: 632-637, 2013.
2. Hui ES, Udofa EA, Soto J, Vanderhoof VH, Zachman K, Tong ZB and Nelson LM: Investigation of the human stem cell factor KIT ligand gene, KITLG, in women with 46,XX spontaneous premature ovarian failure. Fertil Steril 85: 1502-1507, 2006.

3. Kokcu A: Premature ovarian failure from current perspective. Gynecol Endocrinol 26: 555-562, 2010.

4. Cartwright B, Robinson J and Rymer J: Treatment of premature ovarian failure trial: Description of an ongoing clinical trial. Menopause Int 16: 18-22, 2010.

5. Liu J, Malhotra R, Voltarelli J, Stracieri AB, Oliveira L, Simoes BP, Ball ED and Carrier E: Ovarian recovery after stem cell transplantation. Bone Marrow Transplant 41: 275-278, 2008.

6. Nippita TA and Baber RJ: Premature ovarian failure: A review. Climacteric 10: 11-22, 2007.

7. Goswami D and Conway GS: Premature ovarian failure. Horm Res 68: 196-202, 2007.

8. Goswami D and Conway GS: Premature ovarian failure. Hum Reprod Update 11: 391-410, 2005.

9. Edessy M, Hosni HN, Wafa Y, Bakry S, Shady Y and Kamel M: Stem cells transplantation in premature ovarian failure. World J Med Sci 10: 12-16, 2014.

10. Edessy M, Hosni HN, Shady Y, Waf Y, Bakr S and Kamel M: Autologous stem cells therapy, the first baby of idiopathic premature ovarian failure. Acta Med Int 3: 19-23, 2016.

11. Antoine C, Ameye L, Paesmans M and Rozenberg S: Systematic review about breast cancer incidence in relation to hormone replacement therapy use. Climacteric 17: 116-132, 2014.

12. Liu T, Li Q, Wang S, Chen $\mathrm{C}$ and Zheng J: Transplantation of ovarian granulosa-like cells derived from human induced pluripotent stem cells for the treatment of murine premature ovarian failure. Mol Med Rep 13: 5053-5058, 2016.

13. Agung M, Ochi M, Yanada S, Adachi N, Izuta Y, Yamasaki T and Toda K: Mobilization of bone marrow-derived mesenchymal stem cells into the injured tissues after intraarticular injection and their contribution to tissue regeneration. Knee Surg Sports Traumatol Arthrosc 14: 1307-1314, 2006.

14. Blumenfeld Z, Patel B, Leiba R and Zuckerman T: Gonadotropinreleasing hormone agonist may minimize premature ovarian failure in young women undergoing autologous stem cell transplantation. Fertil Steril 98: 1266-1270.e1, 2012.

15. Cheng YC, Saliba RM, Rondón G, Giralt SA, Lu KH, Bodurka DC, Gershenson DM, Champlin RE and Ueno NT: Low prevalence of premature ovarian failure in women given reduced-intensity conditioning regimens for hematopoietic stem-cell transplantation. Haematologica 90: 1725-1726, 2005.

16. Balachandar S, Dunkel IJ, Khakoo Y, Wolden S, Allen J and Sklar CA: Ovarian function in survivors of childhood medulloblastoma: Impact of reduced dose craniospinal irradiation and high-dose chemotherapy with autologous stem cell rescue. Pediatr Blood Cancer 62: 317-321, 2015.

17. Badawy A, Sobh MA, Ahdy M and Abdelhafez MS: Bone marrow mesenchymal stem cell repair of cyclophosphamide-induced ovarian insufficiency in a mouse model. Int J Womens Health 9: 441-447, 2017.

18. Fatemi HM, Bourgain C, Donoso P, Blockeel C, Papanikolaou EG, Popovic-Todorovic B and Devroey P: Effect of oral administration of dydrogestrone versus vaginal administration of natural micronized progesterone on the secretory transformation of endometrium and luteal endocrine profile in patients with premature ovarian failure: A proof of concept. Hum Reprod 22: 1260-1263, 2007.

19. Xu Y, Guo S, Wei C, Li H, Chen L, Yin C and Zhang C: The comparison of adipose stem cell and placental stem cell in secretion characteristics and in facial antiaging. Stem Cells Int 2016: 7315830, 2016.

20. Higgins J, Thompson S, Deeks J and Altman D: Statistical heterogeneity in systematic reviews of clinical trials: A critical appraisal of guidelines and practice. J Health Serv Res Policy 7: 51-61, 2002.

21. Egger M, Davey Smith G, Schneider M and Minder C: Bias in meta-analysis detected by a simple, graphical test. BMJ 315: 629-634, 1997.

22. Elfayomy AK, Almasry SM,El-Tarhouny SA and Eldomiaty MA: Human umbilical cord blood-mesenchymal stem cells transplantation renovates the ovarian surface epithelium in a rat model of premature ovarian failure: Possible direct and indirect effects. Tissue Cell 48: 370-382, 2016.

23. Song D, Zhong Y, Qian C, Zou Q, Ou J, Shi Y, Gao L, Wang G, Liu Z, Li H, et al: Human umbilical cord mesenchymal stem cells therapy in cyclophosphamide-induced premature ovarian failure rat model. Biomed Res Int 2016: 2517514, 2016. 
24. Su J, Ding L, Cheng J, Yang J, Li X, Yan G, Sun H, Dai J and $\mathrm{Hu}$ Y: Transplantation of adipose-derived stem cells combined with collagen scaffolds restores ovarian function in a rat model of premature ovarian insufficiency. Hum Reprod 31: 1075-1086, 2016.

25. Zhang Q, Xu M, Yao X, Li T, Wang Q and Lai D: Human amniotic epithelial cells inhibit granulosa cell apoptosis induced by chemotherapy and restore the fertility. Stem Cell Res Ther 6: 152, 2015.

26. Dang J, Jin Z, Liu X, Hu D and Wang Z: Human cord blood mononuclear cell transplantation for the treatment of premature ovarian failure in nude mice. Int J Clin Exp Med 8: 4122-4127, 2015.

27. Lai D, Wang F, Yao X, Zhang Q, Wu X and Xiang C: Human endometrial mesenchymal stem cells restore ovarian function through improving the renewal of germline stem cells in a mouse model of premature ovarian failure. J Transl Med 13: 155, 2015.

28. Liu T, Huang Y, Zhang J, Qin W, Chi H, Chen J, Yu Z and Chen C: Transplantation of human menstrual blood stem cells to treat premature ovarian failure in mouse model. Stem Cells Dev 23: 1548-1557, 2014

29. Kilic S, Pinarli F, Ozogul C, Tasdemir N, Naz Sarac G and Delibasi T: Protection from cyclophosphamide-induced ovarian damage with bone marrow-derived mesenchymal stem cells during puberty. Gynecol Endocrinol 30: 135-140, 2014.

30. Liu J, Zhang H, Zhang Y, Li N, Wen Y, Cao F, Ai H and Xue X: Homing and restorative effects of bone marrow-derived mesenchymal stem cells on cisplatin injured ovaries in rats. Mol Cells 37: 865-872, 2014.

31. Lai D, Wang F, Dong Z and Zhang Q: Skin-derived mesenchymal stem cells help restore function to ovaries in a premature ovarian failure mouse model. PLoS One 9: e98749, 2014

32. Wang F, Wang L, Yao X, Lai D and Guo L: Human amniotic epithelial cells can differentiate into granulosa cells and restore folliculogenesis in a mouse model of chemotherapy-induced premature ovarian failure. Stem Cell Res Ther 4: 124, 2013.

33. Liu T, Qin W, Huang Y, Zhao Y and Wang J: Induction of estrogen-sensitive epithelial cells derived from human-induced pluripotent stem cells to repair ovarian function in a chemotherapyinduced mouse model of premature ovarian failure. DNA Cell Biol 32: 685-698, 2013.

34. Wang S, Yu L, Sun M, Mu S, Wang C, Wang D and Yao Y: The therapeutic potential of umbilical cord mesenchymal stem cells in mice premature ovarian failure. Biomed Res Int 2013: 690491, 2013.
35. Fu X, He Y, Xie C and Liu W: Bone marrow mesenchymal stem cell transplantation improves ovarian function and structure in rats with chemotherapy-induced ovarian damage. Cytotherapy 10: 353-363, 2008

36. Lee HJ, Selesniemi K, Niikura Y, Niikura T, Klein R, Dombkowski DM and Tilly JL: Bone marrow transplantation generates immature oocytes and rescues long-term fertility in a preclinical mouse model of chemotherapy-induced premature ovarian failure. J Clin Oncol 25: 3198-3204, 2007.

37. Jiang $X$, Zhang $\mathrm{H}$ and Teng M: Effectiveness of autologous stem cell therapy for the treatment of lower extremity ulcers: A systematic review and meta-analysis. Medicine (Baltimore) 95: e2716, 2016.

38. Kwee J, Schats R, McDonnell J, Themmen A, de Jong F and Lambalk C: Evaluation of anti-Müllerian hormone as a test for the prediction of ovarian reserve. Fertil Steril 90: 737-743, 2008.

39. Şükür YE, Kıvançlı IB and Ozmen B: Ovarian aging and premature ovarian failure. J Turk Ger Gynecol Assoc 15: 190-196, 2014

40. Abd-Allah SH, Shalaby SM, Pasha HF, El-Shal AS, Raafat N, Shabrawy SM, Awad HA, Amer MG, Gharib MA, El Gendy EA, et al: Mechanistic action of mesenchymal stem cell injection in the treatment of chemically induced ovarian failure in rabbits. Cytotherapy 15: 64-75, 2013.

41. Roness H, Kalich-Philosoph L and Meirow D: Prevention of chemotherapy-induced ovarian damage: Possible roles for hormonal and non-hormonal attenuating agents. Hum Reprod Update 20: 759-774, 2014.

42. Thomakos N, Trachana SP, Koutroumpa I, Rodolakis A and Gavalas NG: Molecular aspects and clinical methods for preserving ovarian reserves in women receiving cancer treatment. Clin Exp Obstet Gynecol 42: 416-425, 2015.

43. Centre for Evidence-Based Medicine: Oxford centre for evidence-based medicine-levels of evidence. https://www.cebm. net/2009/06/oxford-centre-evidence-based-medicine-levelsevidence-march-2009/. Accessed February 8, 2018.

This work is licensed under a Creative Commons Attribution-NonCommercial-NoDerivatives 4.0 International (CC BY-NC-ND 4.0) License. 